\title{
Impact of simultaneous retention of micropollutants and laccase on micropollutant degradation in enzymatic membrane bioreactor
}

Muhammad B. Asif ${ }^{1}$, Faisal I. Hai ${ }^{1,}$, Bipro R. Dhar ${ }^{2}$, Huu H. Ngo ${ }^{3}$, Wenshan Guo ${ }^{3}$,

Veeriah Jegatheesan ${ }^{4}$, William E. Price ${ }^{5}$, Long D. Nghiem ${ }^{1,3}$, Kazuo Yamamoto ${ }^{6}$

1 Strategic Water Infrastructure Lab, School of Civil, Mining and Environmental Engineering, University of Wollongong, Wollongong NSW 2522, Australia.

2 Department of Civil and Environmental Engineering, School of Mining \& Petroleum Engineering, University of Alberta, Edmonton, AB T6G 1H9, Canada

${ }^{3}$ Centre for Technology in Water and Wastewater, School of Civil and Environmental Engineering, University of Technology Sydney, Sydney, NWS 2007, Australia

${ }^{4}$ School of Engineering, RMIT University, Melbourne, VIC 3000, Australia

${ }^{5}$ Strategic Water Infrastructure Lab, School of Chemistry, University of Wollongong, Wollongong NSW 2522, Australia.

6 Environmental Science Centre, Department of Urban Engineering, University of Tokyo, Tokyo 113-0033, Japan

* Corresponding author: faisal@uow.edu.au; Tel.: +61-2-42213054 


\begin{abstract}
This study systematically compares the performance of ultrafiltration (UF) and nanofiltration (NF)- based enzymatic membrane bioreactors (EMBRs) for the degradation of five micropollutants, namely atrazine, carbamazepine, sulfamethoxazole, diclofenac and oxybenzone to elucidate the impact of effective membrane retention of micropollutants on their degradation. Based on the permeate quality, NF-EMBR achieved 92-99.9\% micropollutant removal (i.e., biodegradation + membrane retention), while the removal of these micropollutants by UF-EMBR varied from $20-85 \%$. Mass balance analysis revealed that micropollutant degradation was improved by $15-30 \%$ in NF-EMBR as compared to UFEMBR, which could be attributed to the prolonged contact time between laccase and micropollutants following their effective retention by the NF membrane. A small decline in permeate flux was observed during EMBR operation. However, the flux could be recovered by flushing the membrane with permeate.
\end{abstract}

Keywords: High retention membrane; Enzymatic membrane bioreactor Laccase-catalyzed degradation; Micropollutants; Nanofiltration membrane; Ultrafiltration membrane 


\section{Introduction}

A wide range of micropollutants, e.g., pharmaceuticals, personal care products and pesticides, are detected in natural water bodies including surface water and groundwater at trace concentrations ranging from a few ng/L to a tens of $\mu \mathrm{g} / \mathrm{L}$. Because micropollutants are ineffectively removed from municipal wastewater via conventional wastewater treatment processes, wastewater treatment plant effluent is a major source of micropollutants in natural water bodies (Hai et al., 2014; Luo et al., 2014b). Owing to their potentially harmful effects on aquatic ecosystem and human health, in recent years, the widespread occurrence of micropollutants in freshwater sources has triggered specific water quality guidelines (Hai et al., 2018; Lapworth et al., 2012). Therefore, an efficient treatment process is required for the removal of micropollutants from water and wastewater.

Several physicochemical and biological techniques such as membrane bioreactors, activated carbon and advanced oxidation processes have been assessed for effective removal of micropollutants (Luo et al., 2014b). Enzymatic degradation has gained significant attention in the recent years (Yang et al., 2013). Unlike the conventional biological treatment processes, the oxidoreductase enzyme laccase can catalyze the oxidation or degradation of recalcitrant micropollutants using dissolved oxygen as a co-factor. It typically involves the transfer of an electron from a substrate to the active sites of laccase followed by conversion of dissolved oxygen to water (Asif et al., 2017c; Gonçalves et al., 2015). The characteristics of active sites of laccase have been studied by using a combination of spectroscopic and crystallography techniques (Claus, 2004; Demarche et al., 2012). Briefly, laccase active sites consist of four copper atoms, and can be classified into following categories: (i) Type 1 containing one copper atom; (ii) Type II containing one copper atom; and (iii) Type III containing a pair of copper atoms. During the degradation process, reduction of Type I copper site occurs due to the transfer of an electron from a substrate to the laccase. This promotes the transfer of an 
electron to Type II and Type III active sites where dissolved oxygen is reduced, and release of water takes place (Claus, 2004; Gonçalves et al., 2015). In general, degradation of micropollutants by laccase is strongly influenced by their molecular properties. Micropollutants having strong electron donating functional groups (EDGs), particularly the phenolic group, are more susceptible to degradation by laccase as compared to those containing electron withdrawing functional groups (EWGs) (Ji et al., 2016; Yang et al., 2013).

Enzymatic degradation of micropollutants has been predominantly investigated in batch bioreactors due to the concern of enzyme washout along with the treated effluent from a continuous flow reactor. This problem could be addressed either by immobilizing the enzyme onto a carrier (Datta et al., 2013) or by coupling an enzymatic bioreactor to a membrane of suitable molecular weight cut-off (Nguyen et al., 2014a). The use of enzymatic membrane bioreactors (EMBR) offers several advantages over enzyme immobilization including negligible mass transfer limitations, effective enzyme retention, and ease of enzyme replenishment during long term operation (Modin et al., 2014).

Recent studies have explored ultrafiltration enzymatic membrane bioreactors (UF-EMBR) for micropollutants removal (Lloret et al., 2012; Nguyen et al., 2014a) because they can potentially retain the enzyme (i.e., laccase), thus allowing continuous micropollutant degradation within the UF-EMBR without the requirement of continuous dosing of laccase. However, UF membranes in practice cannot effectively retain micropollutants. Thus, micropollutants that are not readily degraded by laccase can still pass through the UF membrane, consequently requiring an additional post-treatment process for their effective removal. An innovative approach to this is to combine a high retention membrane such as nanofiltration (NF) membrane with an enzymatic bioreactor. To date, performance of the NFEMBR concept has not been systematically studied. 
Standalone nanofiltration has been studied extensively for effective removal of micropollutants from secondary treated wastewater or freshwater. However, the concentrate produced during nanofiltration requires further treatment before safe disposal (GarcíaVaquero et al., 2014). Instead of an additional step for NF concentrate treatment, its combination with an enzymatic bioreactor would provide degradation and separation of micropollutants in a single step.

It is also possible that the prolonged contact time between laccase and micropollutants due to their effective retention in the enzymatic bioreactor by the NF membrane may facilitate enhanced micropollutant degradation. The beneficial effect of longer retention of micropollutants on their degradation has been alluded to for other designs of enzymatic bioreactors, but has not been clearly demonstrated. For example, Nguyen et al. (2016a) attributed enhanced degradation of micropollutants by an activated carbon-bound laccase system to their simultaneous adsorption (i.e., retention) and degradation. In another study, efficient micropollutant degradation was achieved by integrating an enzymatic bioreactor with the membrane distillation process (Asif et al., 2018). Membrane distillation retained both laccase and micropollutants and thus facilitated their long contact time. However, since a suitable "control" EMBR, which can only retain laccase but not the micropollutants, was not operated, the mechanisms of enhanced micropollutants removal could not be elucidated in that study.

The study aims to elucidate the effect of simultaneous retention of micropollutants and laccase on micropollutant degradation. This is achieved by studying the performance of an UF-EMBR (“control”) and NF-EMBR under identical operating conditions such as hydraulic retention time (HRT) and micropollutant loading rate. Overall this study systematically analyses the role of the UF and NF membranes for the removal of micropollutants, and also elucidates the micropollutant removal mechanism depending on the molecular properties of 
the micropollutants studied. Finally, the hydraulic performance of the membranes within the EMBRs is compared to confirm the stability of the process developed.

\section{Materials and Methods}

\subsection{Micropollutants, laccase and membranes}

A synthetic wastewater containing a mixture of a pesticide (atrazine) and four pharmaceuticals and personal care products (carbamazepine, sulfamethoxazole, diclofenac and oxybenzone) each at a concentration of $1000 \mu \mathrm{g} / \mathrm{L}$ in Milli-Q water $(\mathrm{pH} \sim 7)$ was prepared for this study. These micropollutants were selected based on their widespread occurrence in wastewater and natural water bodies (Lapworth et al., 2012; Luo et al., 2014b). Relevant physicochemical properties of these micropollutants are listed in Table 1. All the micropollutants were purchased from Sigma-Aldrich (Sydney, NSW, Australia) and were of analytical grade (purity $>98 \%$ ). A stock solution $(2 \mathrm{~g} / \mathrm{L})$ containing the mixture of micropollutants was prepared in pure methanol and stored at $-18^{\circ} \mathrm{C}$ in the dark.

\section{[Table 1]}

Laccase from genetically modified Aspergillus oryzae was obtained from Novozymes Australia Pty. Ltd. (Sydney, NSW, Australia). According to the supplier, the laccase stock solution had a density of $1.12 \mathrm{~g} / \mathrm{mL}$, purity of approximately $10 \%(\mathrm{w} / \mathrm{w})$ and molecular weight of $56 \mathrm{kDa}$. Enzymatic activity of laccase stock solution was $190 \mathrm{mM}(\mathrm{DMP}) / \mathrm{min}$, which was measured using 2,6-dimethoxy phenol (DMP) as substrate at $20^{\circ} \mathrm{C}$ and $\mathrm{pH}=4.5$ (See section 2.4). The oxidation-reduction potential (ORP) of laccase that was measured using an ORP meter (WP-80D dual pH-mV meter, Thermo Fisher Scientific, Australia) was $0.28 \mathrm{mV}$. Commercially available flat-sheet UF and NF membranes were used in this study and their properties are given in Table 2.

\section{[Table 2]}




\subsection{Experimental setup}

A laboratory-scale cross-flow filtration setup combined to an enzymatic bioreactor was used in this study (Figure 1). A detailed description of the filtration system is given elsewhere (Fujioka et al., 2013). Briefly, this system mainly consists of a stainless steel enzymatic bioreactor, high pressure pump (Hydra-Cell, Wanner Engineering Inc., Minneapolis, MN, USA), stainless steel membrane cell, and bypass and back-pressure valves (Swagelok, Solon, $\mathrm{OH}$, USA). The membrane cell has a channel height of $2 \mathrm{~mm}$ that holds the flat-sheet NF or UF membrane. A digital flow meter (FlowCal, GJC Instruments Ltd, Chester, UK) was connected to the permeate line for monitoring the permeate flux. The cross-flow velocity and temperature was maintained at $40.2 \mathrm{~cm} / \mathrm{s}$ and $25^{\circ} \mathrm{C}$, respectively in all experiments.

[Figure 1]

\subsection{Enzymatic membrane bioreactor operation and experimental protocols}

Before the start of each experiment, the NF membrane was compacted using Milli-Q water at 10 bar until the flux is stabilized. However, the recirculation flow rate of $40.2 \mathrm{~cm} / \mathrm{s}$ without applying any pressure was adequate to compact the UF membrane and achieve a permeate flux equivalent to that of the NF membrane. Enzymatic bioreactors coupled to the UF or NF membrane were separately operated in two operating modes: (i) full recirculation mode; and (ii) continuous-flow mode as explained below.

\subsubsection{UF/NF-EMBR operation in full recirculation mode}

The working volume of the enzymatic bioreactor was kept at $3 \mathrm{~L}$ in all experiments. In full recirculation mode, UF/NF-EMBRs were operated for a period of $24 \mathrm{~h}$, and the membrane permeate was continuously returned back to the enzymatic bioreactor. The NF-EMBR was operated at a pressure of 8 bar and cross-flow velocity of $40.2 \mathrm{~cm} / \mathrm{s}$, which corresponds to an initial permeate flux of $6.9 \mathrm{~L} / \mathrm{m}^{2} \mathrm{~h}$ bar. Laccase was directly added to the enzymatic 
bioreactor to achieve an initial laccase activity of $180-185 \mu \mathrm{M}_{(\mathrm{DMP})} / \mathrm{min}$. This laccase activity was selected based on that reported for previously developed UF-EMBRs (Nguyen et al., 2014a; Nguyen et al., 2016b). Stock solution containing the micropollutant mixture was added to the enzymatic bioreactor to obtain a concentration of $1000 \mu \mathrm{g} / \mathrm{L}$ of each micropollutant. However, the actual initial measured concentrations of atrazine, carbamazepine, sulfamethoxazole, diclofenac and oxybenzone were $1100 \pm 20,1050 \pm 40$, $1120 \pm 80,1070 \pm 40$ and $1000 \pm 30 \mu \mathrm{g} / \mathrm{L}(\mathrm{n}=4)$, respectively.

All operating parameters for UF-EMBR were identical to that of NF-EMBR except the applied pressure as explained above. The EMBRs were first operated to confirm retention of laccase and micropollutants by the membrane and check the stability of laccase during EMBR operation. Duplicate samples were collected from the membrane permeate at 2, 4, 8 and $24 \mathrm{~h}$ for measuring laccase activity and micropollutant removal. Micropollutant removal was quantified as $\mathrm{R}(\%)=100 \times\left(1-\mathrm{C}_{\mathrm{t}} / \mathrm{C}_{\mathrm{o}}\right)$, where $\mathrm{C}_{\mathrm{o}}$ and $\mathrm{C}_{\mathrm{t}}$ are initial concentration $(0 \mathrm{~h})$ and concentration at the time of sampling, respectively. The laccase activity assay is described in section 2.4 .

\subsubsection{UF/NF-EMBR operation in continuous-flow mode}

All the operating conditions in continuous-flow mode were same as described in section 2.3.1, except that the synthetic wastewater containing the mixture of micropollutants was continuously fed into the enzymatic bioreactors at a loading rate of $1.44 \mathrm{mg} / \mathrm{L} . \mathrm{d}$ for each micropollutant. A peristaltic pump (Masterflex, Vernon Hills, IL, USA) was used for continuous feeding. Based on the initial permeate flux of the membranes (i.e., $6.9 \mathrm{~L} / \mathrm{m}^{2} \mathrm{~h}$ bar), the hydraulic retention time (HRT) of the EMBRs was $16 \mathrm{~h}$. The EMBRs were each operated continuously for a period of $48 \mathrm{~h}$ (i.e., $3 \times \mathrm{HRT}$ ). During each run, duplicate samples were collected from the enzymatic bioreactor and membrane permeate at specific intervals (i.e., 6, 12, 16, 24, 32, 38 and 48 h) for measuring laccase activity and micropollutant 
removal. At the end of UF/NF-EMBR operation, the clean water flux was measured for $1 \mathrm{~h}$ using Milli-Q water to assess membrane fouling and flux recovery. Removal efficiency by laccase ( $\left.R_{\text {degradation}}\right)$ and the membrane (Rdegradation+membrane) was measured using equation (1) and (2), respectively:

$$
\begin{aligned}
& \mathrm{R}_{\text {biodegradation }}=100 \times\left(1-\mathrm{C}_{\mathrm{EBR}} / \mathrm{C}_{\mathrm{f}}\right) \\
& \mathrm{R}_{(\text {biodegradation }+ \text { membrane })}=100 \times\left(1-\mathrm{C}_{\mathrm{p}} / \mathrm{C}_{\mathrm{f}}\right)
\end{aligned}
$$

where, $\mathrm{C}_{\mathrm{f}}, \mathrm{C}_{\mathrm{EBR}}$ and $\mathrm{C}_{\mathrm{p}}$ are the concentration $(\mu \mathrm{g} / \mathrm{L})$ of a specific micropollutant in the feed, enzymatic bioreactor and permeate, respectively. The mass of micropollutants degraded by laccase was calculated as follows:

$$
\mathrm{C}_{\mathrm{f}} \times \mathrm{V}_{\mathrm{f}}=\left(\mathrm{C}_{\mathrm{EBR}} \times \mathrm{V}_{\mathrm{EBR}}\right)+\left(\mathrm{C}_{\mathrm{p}} \times \mathrm{V}_{\mathrm{p}}\right)+\text { biodegradation/biotransformation }
$$

where, $V_{f}, V_{\text {EBR }}$ and $V_{p}$ represents the volume of feed, enzymatic bioreactor and permeate, respectively.

\subsection{Analytical methods}

Micropollutant concentration in the enzymatic bioreactor and membrane permeate was measured by High-performance liquid chromatography (HPLC) (Shimadzu, Kyoto, Japan) at the detection wavelength of $280 \mathrm{~nm}$ using a method reported previously (Nguyen et al., 2014b). Briefly, the HPLC system was equipped with a UV-Vis detector and C-18 column $(300 \times 4.6 \mathrm{~mm})$ having a pore size of $5 \mu \mathrm{m}$ (Supelco Drug Discovery, Sigma Aldrich, Sydney, NSW, Australia). Milli-Q water buffered with $25 \mathrm{mM} \mathrm{KH}_{2} \mathrm{PO}_{4}$ and HPLC grade acetonitrile were used as the mobile phase for micropollutant quantification. Two eluents, namely eluent A (20\% acetonitrile $+80 \%$ buffer, v/v) and eluent B ( $80 \%$ acetonitrile $+20 \%$ buffer, v/v), were passed through the $\mathrm{C}-18$ column at a flow rate of $0.7 \mathrm{~mL} / \mathrm{min}$ for $30 \mathrm{~min}$ in time dependent gradients as follows: [Time (min), A (\%)]: [0, 85], [8, 40], [10, 0], [22, 0], [24, 85]. The gradient of eluent B was then automatically adjusted as follows: [Time (min), B 
$(\%)]:[0,15],[8,60],[10,100],[22,100],[24,15]$. The limit of detection (LOD) for this method was approximately $10 \mu \mathrm{g} / \mathrm{L}$.

Laccase activity was measured as described elsewhere (Asif et al., 2018). Oxidation of 2,6dimethoxyl phenol (DMP) by laccase was monitored for two minutes in $100 \mathrm{mM}$ sodium citrate buffer ( $\mathrm{pH} 4.5)$. The change in the color due to the oxidation of the substrate (DMP) was measured at $468 \mathrm{~nm}$ using a UV-Vis spectrometer (DR3900, HACH, Loveland, Colorado, USA). Enzymatic activity $\left(\mu \mathrm{M}_{(\mathrm{DMP})} / \mathrm{min}\right)$ was then calculated from a molar extinction coefficient of $49.6 / \mathrm{mM} \mathrm{cm}$.

\section{Results and discussion}

\subsection{Laccase and micropollutant retention by the membranes}

Coupling a membrane to the enzymatic bioreactor can prevent washout of the enzyme along with treated effluent. The flat-sheet UF and NF membranes used in this study have not been tested before for laccase retention. Hence, effective retention of laccase was studied by operating UF/NF-EMBRs in full recirculation mode. Laccase activity in NF-EMBR permeate remained undetected throughout operation as shown in Supplementary data, thus confirming effective retention of laccase by the NF membrane. On the other hand, no laccase activity was detected in the permeate during the first $4 \mathrm{~h}$ of UF-EMBR operation in full recirculation mode, but a small laccase activity of 5-7 $\mu \mathrm{M}_{(\mathrm{DMP})} / \mathrm{min}$ (i.e., still above $95 \%$ laccase retention) was measured in UF-permeate samples for the rest of the experiment. In previously developed UF-EMBR, hollow fiber UF membranes with molecular weight cutoff (MWCO) of 6-10 kDa effectively retained laccase in the enzymatic bioreactor (Lloret et al., 2012; Nguyen et al., 2014a). Although the MWCO of the flat-sheet UF membrane (30 KDa) used in this study was smaller than the size of laccase $(56 \mathrm{KDa})$, slight passage of laccase through the UF membrane can be attributed to its diffusion into the permeate following the formation of a laccase gel-layer on the membrane surface that was visible to the naked eye. The enzyme gel- 
layer formed on the UF membrane can be seen in the picture given in Supplementary Data. In addition, membrane pore size may be non-uniform, and presence of pores with diameter greater than the average pore size can increase the effective MWCO of a membrane. Furthermore, depending on water matrix (e.g., ionic strength and $\mathrm{pH}$ ) and membrane properties (e.g., surface charge, hydrophobicity and pore size), chemicals may permeate even through the membrane with a smaller MWCO. Similar observations were made when two enzymes, namely, lysozyme and protease were concentrated using polysulfone and polyethersulfone ultrafiltration membranes, respectively (Salgin et al., 2006; Varzakas et al., 1999).

Despite complete laccase retention by the NF membrane, the laccase activity in the enzymatic bioreactor dropped by approximately 18\% after operating NF-EMBR in full recirculation mode for $24 \mathrm{~h}$, possibly due to laccase denaturation. Laccase denaturation can be attributed to various factors such as chemical and biological inhibitors (Asif et al., 2017a). However, in absence of any known inhibitors, laccase activity reduction in this study was possibly due to the shear stress caused by filtration (Akay et al., 2002; Krstić et al., 2007). In addition, the transformation products formed following the degradation of micropollutants can attach to the active sites of laccase, consequently inhibiting laccase activity (Purich, 2010). Based on the observed laccase activity profile during continuous-flow operation of EMBRs, a small dose of laccase (i.e., $250 \mu \mathrm{L}$ per litre of bioreactor volume) was re-injected into the enzymatic bioreactor every $24 \mathrm{~h}$ to maintain a laccase activity of $180-185 \mu \mathrm{M}(\mathrm{DMP}) / \mathrm{min}$. The laccase activity profile in continuous-flow UF/NF-EMBRs is shown in the Supplementary Data.

The results of NF-EMBR operation in full recirculation mode confirmed above $95 \%$ retention of the micropollutants by the NF membrane. Conversely, micropollutant rejection by the UF membrane varied between 1\% (Sulfamethoxazole) and 5\% (diclofenac). The rejections of 
micropollutants by both membranes are shown in Supplementary Data. Micropollutant removal mechanisms by the continuous-flow EMBRs, including removal by the membrane as well as enzymatic degradation are explained in the next sections.

\subsection{Performance of UF/NF-EMBRs under continuous-flow mode}

\subsubsection{Overall removal of micropollutants}

In this study, NF-EMBR achieved 92 to over 99\% removal of the micropollutants (Figure 2). In general, NF membranes can remove micropollutants via the following mechanisms: (i) size exclusion; (ii) adsorption; and (iii) electrostatic interaction (Dang et al., 2014; Taheran et al., 2016). Micropollutants having a molecular weight higher than $200 \mathrm{~g} / \mathrm{mol}$ have been reported to be effectively rejected by the NF90 membrane (Luo et al., 2014a). Because the molecular weight of the selected micropollutants in this study was above $200 \mathrm{~g} / \mathrm{mole}$, effective rejection (92-99\%) could be attributed to size exclusion mechanism. Moreover, charge repulsion between the negatively charged NF membrane (Table 2) and negatively charged micropollutants (i.e., diclofenac, sulfamethoxazole and atrazine) could be responsible for their rejection by the NF membrane in the NF-EMBR. Adsorption of hydrophobic micropollutants $(\log \mathrm{D}>3.2)$, which are generally neutral at $\mathrm{pH}=7$, on membrane surface has been reported to result in effective rejection by the NF membrane at the initial stage of operation. However, their rejection could reduce gradually with time due to the diffusion of hydrophobic micropollutants into permeate (Naghdi et al., 2016; Taheran et al., 2016). In this study, the NF-EMBR achieved above $99 \%$ removal of a hydrophobic micropollutant, namely oxybenzone $(\log \mathrm{D}=3.99)$, because it was highly degraded $(\sim 99 \%)$ by laccase as discussed in section 3.2.2.

[Figure 2]

The overall removal of the micropollutants by the NF-EMBR (as indicated by micropollutant concentration in the membrane permeate) was $10-80 \%$ higher than that by the UF-EMBR 
(Figure 2). UF membranes are not expected to remove micropollutants via size exclusion. However, it was observed that micropollutants were partially retained by the UF membrane. To assess the role of the UF membrane in micropollutant retention, the ratio of each micropollutant concentration in membrane permeate and enzymatic bioreactor (P/EBR ratio) is presented in Figure 3. Previously, adsorption of hydrophobic micropollutants (i.e., log D >3.2) on the enzyme gel-layer formed on the surface of a hollow fiber polyacrylonitrile membrane has been reported (Nguyen et al., 2015). In a study by Nguyen et al. (2014a), membrane was rinsed with $1 \mathrm{~L}$ ultrapure Milli-Q water after experiment and the cleaning solution showed an enzymatic activity of $60 \mu \mathrm{M}_{(\mathrm{DMP})} / \mathrm{min}$. Thus, it was demonstrated that an enzyme gel-layer was formed due to the accumulation of laccase on membrane surface during the operation of UF-EMBR (Nguyen et al., 2014a).

In this study, oxybenzone, which is a hydrophobic micropollutant $\left(\log \mathrm{D}_{\mathrm{pH}=7}=3.99\right)$, was highly retained by the gel layer over the UF membrane (P/EBR ratio $0.67 \pm 0.04, n=6)$ in UF-MBR. On the other hand, atrazine, diclofenac and sulfamethoxazole, which are hydrophilic micropollutants ( $\log \mathrm{D}_{\mathrm{pH}=7}$ values ranging from -0.22 to 2.63 ) were also retained by the UF membrane to varying extents $(\mathrm{P} / \mathrm{EBR}$ ratio: $0.65-0.91)$. Since these micropollutants (i.e., atrazine, diclofenac and sulfamethoxazole) and the UF membrane are negatively charged at the operating $\mathrm{pH}$ (i.e., approximately 7), their rejection by the UF membrane could be attributed to charge repulsion mechanism. In a study by Garcia-Ivars et al. (2017), partial rejection of anionic micropollutants such as sulfamethoxazole and diclofenac by a ceramic ultrafiltration membrane was observed. The current study confirms that flat-sheet polyvinylidene fluoride ultrafiltration membrane can also partially retain anionic micropollutants.

[Figure 3] 


\subsubsection{Enzymatic degradation}

Micropollutant removal by EMBR comprises of enzymatic degradation and membrane retention. During continuous feeding of wastewater to an EMBR, remaining micropollutants following degradation will mostly pass through the membrane (for UF membrane) or be significantly retained (for NF membrane). The NF membrane is expected to retain micropollutants more effectively than the UF membrane, but the current study seeks to assess if the application of NF can also enhance degradation.

The UF/NF-EMBRs were continuously operated for a duration of $3 \times$ HRT under identical conditions to provide a common basis for comparing the degradation of micropollutants in UF- and NF-EMBRs. The degradation of micropollutants by laccase in UF/NF-EMBR was calculated using Equation (1). Among the selected micropollutants, efficient degradation (8099\%) of oxybenzone was achieved by laccase in both UF- and NF-EMBRs (Figure 4). In addition, its degradation was observed to be above $50 \%$ within the first $6 \mathrm{~h}$ of EMBR operation, which suggested that oxybenzone was easily amenable to degradation by laccase. Since phenols are typical substrates of laccase (Asif et al., 2017a; Yang et al., 2013), high removal of oxybenzone by laccase could be attributed to the presence of a phenolic moiety in its molecule (see Table 1). Indeed, oxybenzone removal by batch and continuous-flow enzymatic bioreactors has been reported to range from 60-99\% (Garcia et al., 2011; Spina et al., 2015). Gago-Ferrero et al. (2012) reported the formation of three degradation products, namely benzophenone-1, 4-hydroxybenzophenone and 4,4'-dihydroxybenzophenone, following laccase-mediated degradation of oxybenzone. Interestingly, despite being inherently amenable to laccase-catalyzed degradation, its degradation was 19\% better in NFEMBR as compared to UF-EMBR (Figure 4). This could be attributed to the effective retention of oxybenzone by the NF membrane, which resulted in its prolonged interaction with laccase. 


\section{[Figure 4]}

In general, non-phenolic micropollutants containing strong EWGs such as amide $\left(-\mathrm{NH}_{2}\right)$ and halogen $(-X)$ are resistant to degradation by laccase (Yang et al., 2013). This is because EWGs redistribute electron density within the molecule, making it less susceptible to electrophile attack (Hai et al., 2011; Tadkaew et al., 2011). In this study, incomplete degradation (10-40\%) of two chlorinated micropollutants, namely diclofenac and atrazine, and two micropollutants containing amide functional groups viz sulfamethoxazole $\left(-\mathrm{NH}_{2}\right)$ and carbamazepine $\left(-\mathrm{NH}_{2}\right)$ was observed in the UF-EMBR (Figure 4). These results are consistent with previously reported performance of laccase in batch and continuous-flow enzymatic bioreactors. For example, Nguyen et al. (2014b) observed less than $25 \%$ removal of atrazine, diclofenac, sulfamethoxazole and carbamazepine in a batch enzymatic bioreactor using laccase from Aspergillus oryzae. In another study, removal of carbamazepine by laccase from Trametes versicolor was less than 10\% (Tran et al., 2010).

In the current study, compared to the UF-EMBR, better degradation (15-30\%) of the nonphenolic micropollutants was achieved by the NF-EMBR (Figure 4). For example, degradation of atrazine and carbamazepine was 29 and 35\%, respectively, by the NF-EMBR, while their degradation was approximately $10 \%$ in UF-EMBR. Similarly, degradation of sulfamethoxazole and diclofenac was $10-30 \%$ better as compared to that achieved by UFEMBR (Figure 4). Transformation products or metabolites formed following an oxidation processes can be more toxic than the parent compound. However, previous studies show that that toxicity of EMBR effluent following degradation of a mixture of micropollutants by laccase does not increase (Ashe et al., 2016; Nguyen et al., 2015). Importantly, when a high retention membrane process (e.g., membrane distillation) is combined with an enzymatic bioreactor, permeate toxicity has been reported to be below the limit of detection (Asif et al., 
2018; Asif et al., 2017b). Since NF membrane is a high retention membrane and can effectively retain micropollutants, NF-EMBR effluent is expected to be non-toxic.

Previous studies indicated that simultaneous retention of laccase and micropollutants may facilitate degradation due to prolonged contact time (Asif et al., 2018; Nguyen et al., 2014b), but did not systematically demonstrate this phenomenon. For instance, enhanced laccasemediated degradation of micropollutants was reported by a membrane distillation (MD)EMBR, where the MD membrane ensured complete retention of both micropollutants and laccase within the enzymatic bioreactor (Asif et al., 2018). However, in that study, performance of the MD-EMBR was not compared to a "control" EMBR where laccase was retained but not the micropollutants. By conducting parallel operation of enzymatic bioreactors coupled with UF (retains only laccase) and NF (retains both laccase and micropollutants) membranes under identical operating conditions, it is demonstrated for the first time in the current study that prolonged contact between laccase and micropollutants following their effective retention by the NF membrane is beneficial for their degradation.

Literature on the performance of an NF based enzymatic membrane bioreactor for micropollutant removal is scarce. To date, only one study (Escalona et al., 2014) has reported the performance of laccase in an NF-EMBR in the recirculation mode (rather than the continuous flow, which is required for scaling up) for a period of only $5 \mathrm{~h}$ and targeting only one micropollutant (i.e., bisphenol A). To improve from the previous study by Escalona et al. (2014), in this study, degradation of a mixture of micropollutants by laccase was assessed by operating the NF-EMBR in continuous-flow mode for a longer duration of $3 \times$ HRT (i.e., 48 h). Indeed, long term operation of a bioreactor is critical to achieve steady state micropollutant degradation (Figure 5).

[Figure 5] 
Notably, in a mixture of micropollutants, phenolic micropollutants can also contribute to the degradation of non-phenolic micropollutants by acting as a 'redox-mediator'. Redoxmediators act as an electron shuttle between laccase and target pollutants, thereby improving the degradation of recalcitrant compounds (Asif et al., 2017c; d'Acunzo et al., 2006; Margot et al., 2013). In a study by Hachi et al. (2017), it was demonstrated that the oxidative coupling agents formed after the degradation of a phenolic micropollutant (i.e., acetaminophen) further contributed to the degradation of a nonphenolic compound (i.e., carbamazepine). Therefore, in addition to the prolonged contact time, it is possible that the effective retention of the oxidative coupling agents formed following the degradation of the phenolic micropollutants such as oxybenzone resulted in the enhanced degradation of the non-phenolic micropollutants such as diclofenac and carbamazepine coexisting in the mixture within the NF-EMBR. This is possibly why the degradation of the recalcitrant micropollutant diclofenac within the NF-EMBR became stable faster after the start of operation in continuous flow mode (Figure 5).

The results of the current study suggest that a NF membrane-coupled enzymatic bioreactor cannot only produce high quality effluent due to effective micropollutant retention, but also achieve improved micropollutant biodegradation (i.e., reduced concentrate disposal).

However, during the treatment of real wastewater, inhibitory effects of wastewater-derived dissolved interfering compounds on laccase can be significant (Asif et al., 2017a). Available modelling studies suggest that in such cases a large number of enzymatic membrane reactors in series may need to be applied (Abejón et al., 2015; de Cazes et al., 2014). Future studies must focus on this aspect.

\subsection{Hydraulic performance of UF/NF-EMBRs}

Variations in the membrane permeate flux of the UF- and NF-EMBR was continuously monitored throughout each experiment (Figure 6). A gradual reduction of the permeate flux 
was observed at the onset of EMBR operation, which could be due to the adsorption of laccase on the surface of the membrane. However, the flux soon stabilized and at the conclusion of operation over a period of $3 \times$ HRT, the flux drop was only $10 \%$ (UF) to $20 \%$ (NF).

\section{[Figure 6]}

The slightly higher flux drop for the NF membrane was probably because of more effective retention of micropollutants and transformation products by the NF membrane (Escalona et al., 2014), which led to formation of a gel layer over the membrane as shown in Supplementary Data. To investigate if the flux was reversible, the pure water flux was measured at the end of each run by flushing the membranes for $1 \mathrm{~h}$ using permeate. The flux recovery in case of the NF-EMBR was $95 \%$ as compared to $99 \%$ in case of UF-EMBR. Therefore, it can be concluded that the fouling was reversible and the flux of the NF membranes can be recovered by flushing the membrane with permeate periodically.

\section{Conclusion}

Removal (i.e., biodegradation + membrane retention) of five micropollutants, namely, atrazine, carbamazepine, sulfamethoxazole, diclofenac and oxybenzone was studied by ultrafiltration (UF) and nanofiltration (NF)-based enzymatic bioreactor (EMBR). Overall removal of micropollutants by UF-EMBR varied from 20-85\%, while NF-EMBR achieved $92-99.9 \%$ micropollutant removal. Notably, the effective retention of the micropollutants within the enzymatic bioreactor by the NF membrane improved (15-30\%) their degradation compared to UF-EMBR. The permeate flux of UF and NF membranes decreased slightly over time but could be recovered by flushing with permeate.

Acknowledgments: This research has been conducted with the support of the Australian Government Research Training Program Scholarship. Novozymes Pty. Ltd., Australia is 
thanked for the provision of enzyme solution. This study was partially funded by the

GeoQuEST Research Centre, University of Wollongong, Australia.

\section{References}

1. Abejón, R., De Cazes, M., Belleville, M.P., Sanchez-Marcano, J. 2015. Large-scale enzymatic membrane reactors for tetracycline degradation in WWTP effluents. Water Research, 73, 118-131.

2. Akay, G., Erhan, E., Keskinler, B., Algur, O.F. 2002. Removal of phenol from wastewater using membrane-immobilized enzymes: Part II. Cross-flow filtration. Journal of Membrane Science, 206(1), 61-68.

3. Ashe, B., Nguyen, L.N., Hai, F.I., Lee, D.-J., van de Merwe, J.P., Leusch, F.D., Price, W.E., Nghiem, L.D. 2016. Impacts of redox-mediator type on trace organic contaminants degradation by laccase: Degradation efficiency, laccase stability and effluent toxicity. International Biodeterioration \& Biodegradation, 113, 169-176.

4. Asif, M.B., Hai, F.I., Hou, J., Price, W.E., Nghiem, L.D. 2017a. Impact of wastewater derived dissolved interfering compounds on growth, enzymatic activity and trace organic contaminant removal of white rot fungi - A critical review. Journal of Environmental Management 201, 89-109.

5. Asif, M.B., Hai, F.I., Kang, J., Van De Merwe, J.P., Leusch, F.D., Price, W.E., Nghiem, L.D. 2018. Biocatalytic degradation of pharmaceuticals, personal care products, industrial chemicals, steroid hormones and pesticides in a membrane distillation-enzymatic bioreactor. Bioresource Technology, 247, 528-536.

6. Asif, M.B., Hai, F.I., Kang, J., Van De Merwe, J.P., Leusch, F.D., Yamamoto, K., Price, W.E., Nghiem, L.D. 2017b. Degradation of Trace Organic Contaminants by a Membrane Distillation-Enzymatic Bioreactor. Applied Sciences, 7(9), 879.

7. Asif, M.B., Hai, F.I., Singh, L., Price, W.E., Nghiem, L.D. 2017c. Degradation of Pharmaceuticals and Personal Care Products by White-Rot Fungi-a Critical Review. Current Pollution Reports, 3(2), 88-103.

8. Claus, H. 2004. Laccases: structure, reactions, distribution. Micron, 35(1), 93-96.

9. d'Acunzo, F., Galli, C., Gentili, P., Sergi, F. 2006. Mechanistic and steric issues in the oxidation of phenolic and non-phenolic compounds by laccase or laccase-mediator systems. The case of bifunctional substrates. New Journal of Chemistry, 30(4), 583-591.

10. Dang, H.Q., Nghiem, L.D., Price, W.E. 2014. Factors governing the rejection of trace organic contaminants by nanofiltration and reverse osmosis membranes. Desalination and Water Treatment, 52(4-6), 589-599.

11. Datta, S., Christena, L.R., Rajaram, Y.R.S. 2013. Enzyme immobilization: an overview on techniques and support materials. 3 Biotech, 3(1), 1-9.

12. de Cazes, M., Belleville, M.P., Petit, E., Llorca, M., Rodríguez-Mozaz, S., de Gunzburg, J., Barceló, D., Sanchez-Marcano, J. 2014. Design and optimization of an enzymatic membrane reactor for tetracycline degradation. Catalysis Today, 236, 146-152.

13. Demarche, P., Junghanns, C., Nair, R.R., Agathos, S.N. 2012. Harnessing the power of enzymes for environmental stewardship. Biotechnology Advances, 30(5), 933-953. 
14. Escalona, I., de Grooth, J., Font, J., Nijmeijer, K. 2014. Removal of BPA by enzyme polymerization using NF membranes. Journal of Membrane Science, 468, 192-201.

15. Fujioka, T., Khan, S.J., McDonald, J.A., Henderson, R.K., Poussade, Y., Drewes, J.E., Nghiem, L.D. 2013. Effects of membrane fouling on N-nitrosamine rejection by nanofiltration and reverse osmosis membranes. Journal of Membrane Science, 427, 311319.

16. Gago-Ferrero, P., Badia-Fabregat, M., Olivares, A., Piña, B., Blánquez, P., Vicent, T., Caminal, G., Díaz-Cruz, M.S., Barceló, D. 2012. Evaluation of fungal- and photodegradation as potential treatments for the removal of sunscreens BP3 and BP1. Science of The Total Environment, 427-428, 355-363.

17. Garcia-Ivars, J., Durá-María, J., Moscardó-Carreño, C., Carbonell-Alcaina, C., AlcainaMiranda, M.-I., Iborra-Clar, M.-I. 2017. Rejection of trace pharmaceutically active compounds present in municipal wastewaters using ceramic fine ultrafiltration membranes: Effect of feed solution $\mathrm{pH}$ and fouling phenomena. Separation and Purification Technology, 175, 58-71.

18. García-Vaquero, N., Lee, E., Jiménez Castañeda, R., Cho, J., López-Ramírez, J.A. 2014. Comparison of drinking water pollutant removal using a nanofiltration pilot plant powered by renewable energy and a conventional treatment facility. Desalination, 347(Supplement C), 94-102.

19. Garcia, H.A., Hoffman, C.M., Kinney, K.A., Lawler, D.F. 2011. Laccase-catalyzed oxidation of oxybenzone in municipal wastewater primary effluent. Water research, 45(5), 1921-1932.

20. Gonçalves, I., Silva, C., Cavaco-Paulo, A. 2015. Ultrasound enhanced laccase applications. Green Chemistry, 17(3), 1362-1374.

21. Hachi, M., Chergui, A., Yeddou, A.R., Selatnia, A., Cabana, H. 2017. Removal of acetaminophen and carbamazepine in single and binary systems with immobilized laccase from Trametes hirsuta. Biocatalysis and Biotransformation, 35(1), 51-62.

22. Hai, F.I., Nghiem, L.D., Khan, S.J., Price, W.E., Yamamoto, K. 2014. Wastewater reuse: Removal of emerging trace organic contaminants. in: Membrane Biological Reactors: Theory, Modeling, Design, Management and Applications to Wastewater Reuse, (Eds.) F.I. Hai, K. Yamamoto, C. Lee, IWA publishing. London, United Kingdom pp. 165-205. (ISBN: 9781780400655).

23. Hai, F.I., Tadkaew, N., McDonald, J.A., Khan, S.J., Nghiem, L.D. 2011. Is halogen content the most important factor in the removal of halogenated trace organics by MBR treatment? Bioresource Technology, 102(10), 6299-6303.

24. Hai, F.I., Yang, S., Asif, M.B., Sencadas, V., Shawkat, S., Sanderson-Smith, M., Gorman, J., Xu, Z.-Q., Yamamoto, K. 2018. Carbamazepine as a Possible Anthropogenic Marker in Water: Occurrences, Toxicological Effects, Regulations and Removal by Wastewater Treatment Technologies. Water, 10(2), 107.

25. Ji, C., Hou, J., Wang, K., Zhang, Y., Chen, V. 2016. Biocatalytic degradation of carbamazepine with immobilized laccase-mediator membrane hybrid reactor. Journal of Membrane Science, 502, 11-20.

26. Krstić, D.M., Antov, M.G., Peričin, D.M., Höflinger, W., Tekić, M.N. 2007. The possibility for improvement of ceramic membrane ultrafiltration of an enzyme solution. Biochemical Engineering Journal, 33(1), 10-15. 
27. Lapworth, D., Baran, N., Stuart, M., Ward, R. 2012. Emerging organic contaminants in groundwater: a review of sources, fate and occurrence. Environmental Pollution, 163, 287303.

28. Lloret, L., Eibes, G., Feijoo, G., Moreira, M.T., Lema, J.M. 2012. Degradation of estrogens by laccase from Myceliophthora thermophila in fed-batch and enzymatic membrane reactors. Journal of Hazardous Materials, 213-214, 175-183.

29. Luo, W., Hai, F.I., Price, W.E., Guo, W., Ngo, H.H., Yamamoto, K., Nghiem, L.D. 2014a. High retention membrane bioreactors: challenges and opportunities. Bioresource Technology, 167, 539-546.

30. Luo, Y., Guo, W., Ngo, H.H., Nghiem, L.D., Hai, F.I., Zhang, J., Liang, S., Wang, X.C. $2014 \mathrm{~b}$. A review on the occurrence of micropollutants in the aquatic environment and their fate and removal during wastewater treatment. Science of the Total Environment, 473, 619641.

31. Margot, J., Maillard, J., Rossi, L., Barry, D.A., Holliger, C. 2013. Influence of treatment conditions on the oxidation of micropollutants by Trametes versicolor laccase. New Biotechnology, 30(6), 803-813.

32. Modin, O., Hai, F.I., Nghiem, L.D., Basile, A., Fukushi, K. 2014. Gas-diffusion, extractive, biocatalytic and electrochemical membrane biological reactors. in: Membrane Biological Reactors: Theory, Modeling, Design, Management and Applications to Wastewater Reuse, (Eds.) F.I. Hai, K. Yamamoto, C. Lee, IWA Publishing. London, United Kingdom, pp. 299334. (ISBN: 9781780400655$)$.

33. Naghdi, M., Taheran, M., Sarma, S.J., Brar, S.K., Ramirez, A.A., Verma, M. 2016. Nanotechnology to Remove Contaminants. in: Nanoscience in Food and Agriculture 1, (Eds.) S. Ranjan, N. Dasgupta, E. Lichtfouse, Springer. Berlin, Germany, pp. 101-128. (ISBN: 9783319393025).

34. Nguyen, L.N., Hai, F.I., Dosseto, A., Richardson, C., Price, W.E., Nghiem, L.D. 2016a. Continuous adsorption and biotransformation of micropollutants by granular activated carbon-bound laccase in a packed-bed enzyme reactor. Bioresource Technology, 210, 108116.

35. Nguyen, L.N., Hai, F.I., Price, W.E., Kang, J., Leusch, F.D., Roddick, F., van de Merwe, J.P., Magram, S.F., Nghiem, L.D. 2015. Degradation of a broad spectrum of trace organic contaminants by an enzymatic membrane reactor: complementary role of membrane retention and enzymatic degradation. International Biodeterioration \& Biodegradation, 99, 115-122.

36. Nguyen, L.N., Hai, F.I., Price, W.E., Leusch, F.D., Roddick, F., McAdam, E.J., Magram, S.F., Nghiem, L.D. 2014a. Continuous biotransformation of bisphenol A and diclofenac by laccase in an enzymatic membrane reactor. International Biodeterioration \& Biodegradation, 95, 25-32.

37. Nguyen, L.N., Hai, F.I., Price, W.E., Leusch, F.D., Roddick, F., Ngo, H.H., Guo, W., Magram, S.F., Nghiem, L.D. 2014b. The effects of mediator and granular activated carbon addition on degradation of trace organic contaminants by an enzymatic membrane reactor. Bioresource Technology, 167, 169-177.

38. Nguyen, L.N., van de Merwe, J.P., Hai, F.I., Leusch, F.D., Kang, J., Price, W.E., Roddick, F., Magram, S.F., Nghiem, L.D. 2016b. Laccase-syringaldehyde-mediated degradation of 
trace organic contaminants in an enzymatic membrane reactor: Removal efficiency and effluent toxicity. Bioresource Technology, 200, 477-484.

39. Purich, D.L. 2010. Enzyme kinetics: catalysis \& control: a reference of theory and bestpractice methods. Elsevier, Amsterdam, Netherlands. (ISBN: 9780123809247).

40. Salgın, S., Takaç, S., Özdamar, T.H. 2006. Effect of ionic environments on the adsorption and diffusion characteristics of serine alkaline protease enzyme in polyethersulfone ultrafiltration membranes. Journal of Colloid and Interface Science, 299(2), 806-814.

41. Spina, F., Cordero, C., Schilirò, T., Sgorbini, B., Pignata, C., Gilli, G., Bicchi, C., Varese, G.C. 2015. Removal of micropollutants by fungal laccases in model solution and municipal wastewater: evaluation of estrogenic activity and ecotoxicity. Journal of Cleaner Poduction, 100, 185-194.

42. Tadkaew, N., Hai, F.I., McDonald, J.A., Khan, S.J., Nghiem, L.D. 2011. Removal of trace organics by MBR treatment: the role of molecular properties. Water Research, 45(8), 24392451.

43. Taheran, M., Brar, S.K., Verma, M., Surampalli, R.Y., Zhang, T.C., Valéro, J.R. 2016. Membrane processes for removal of pharmaceutically active compounds ( $\mathrm{PhACs}$ ) from water and wastewaters. Science of The Total Environment, 547, 60-77.

44. Tran, N.H., Urase, T., Kusakabe, O. 2010. Biodegradation characteristics of pharmaceutical substances by whole fungal culture Trametes versicolor and its laccase. Journal of Water and Environment Technology, 8(2), 125-140.

45. Varzakas, T., Escudero, I., Economou, I.G. 1999. Estimation of endoglucanase and lysozyme effective diffusion coefficients in polysulphone membranes. Journal of Biotechnology, 72(1), 77-83.

46. Yang, S., Hai, F.I., Nghiem, L.D., Price, W.E., Roddick, F., Moreira, M.T., Magram, S.F. 2013. Understanding the factors controlling the removal of trace organic contaminants by white-rot fungi and their lignin modifying enzymes: a critical review. Bioresource Technology, 141, 97-108. 
List of Tables 
Table 1. Physicochemical properties of the micropollutants used in this study

\begin{tabular}{|c|c|c|c|c|c|c|}
\hline Micropollutants & Molecular structure & $\begin{array}{c}\text { Molecular } \\
\text { weight } \\
\text { (g/mole) }\end{array}$ & $\begin{array}{l}\text { Vapor } \\
\text { pressure } \\
(\mathrm{mmHg})\end{array}$ & $\begin{array}{c}\text { Water } \\
\text { solubility at } \\
25^{\circ} \mathrm{C} \\
\text { (mg/L) }\end{array}$ & $\begin{array}{c}\text { Acid } \\
\text { dissociation } \\
\text { coefficient } \\
\left(\mathrm{pK}_{\mathrm{a}}\right)\end{array}$ & $\begin{array}{c}\log D \text { at } \\
\mathrm{pH}=7\end{array}$ \\
\hline Atrazine & & 215.68 & $1.27 \times 10^{-05}$ & 69 & 2.27 & 2.64 \\
\hline Carbamazepine & & 236.27 & $5.78 \times 10^{-07}$ & 220 & 13.94 & 1.89 \\
\hline Sulfamethoxazole & & 253.28 & $1.87 \times 10^{-09}$ & 410 & 5.6 & -0.22 \\
\hline Diclofenac & & 296.15 & $1.59 \times 10^{-07}$ & 30 & 4.18 & 1.77 \\
\hline Oxybenzone & & 228.24 & $5.26 \times 10^{-06}$ & 100 & 7.56 & 3.99 \\
\hline
\end{tabular}

Note: molecular weight, acid dissociation coefficient, log D values, water solubility and vapor pressure values were taken from SciFinder Scholar. 
Table 2. Properties of the membranes used in this study

\begin{tabular}{lcc}
\hline \multicolumn{1}{c}{ Properties } & NF membrane & UF membrane \\
\hline Supplier & Dow/Filmtec & Sterlitech \\
Molecular weight cut-off & $200 \mathrm{Da}$ & $30,000 \mathrm{Da}$ \\
(MWCO) & Polyamide TFC & Polyvinylidene fluoride \\
Active layer & $-20^{\mathrm{a}}$ & $-22^{\mathrm{a}}$ \\
Zeta potential at $\mathrm{pH}=7$ & & \\
\hline a Measured using SurPASS Electrokinetic Analyser (Anton Par GmbH, Graz, Austria) \\
using $1 \mathrm{mM} \mathrm{KCl}$ as background electrolyte solution
\end{tabular}




\section{Figure captions}

Figure 1. Schematics of the lab-scale cross-flow filtration system attached to an enzymatic bioreactor operated in full recirculation mode (a) and continuous-flow mode (b). Arrows show the direction of flow. Laccase retention was first confirmed with a short term (i.e., 24 h) study in full recirculation mode. Further operation of EMBRs were conducted in continuous-flow mode for assessing the impact of micropollutant retention on their degradation. $\mathrm{C}_{\mathrm{f}}, \mathrm{C}_{\mathrm{EBR}}$ and $\mathrm{C}_{\mathrm{p}}$ are the concentration $(\mu \mathrm{g} / \mathrm{L})$ of a specific micropollutant in the feed, enzymatic bioreactor and permeate, respectively. $V_{f}$, $V_{\text {EBR }}$ and $V_{p}$ represent the volume of feed, enzymatic bioreactor and permeate, respectively. A picture of lab-scale EMBR is shown in Supplementary data

Figure 2. Overall removal (i.e., degradation + membrane retention) of micropollutants in UFand NF-EMBRs operated separately at an HRT of $16 \mathrm{~h}$ and micropollutant loading rate of 1.44

$\mathrm{mg} / \mathrm{L} \mathrm{d}$. Data presented as average \pm standard deviation $(n=6)$. The average and standard

deviation was calculated based on the duplicate samples collected at 16, 32 and $48 \mathrm{~h}$

Figure 3. Concentration ratio between membrane permeate and enzymatic bioreactor $(\mathrm{P} / \mathrm{EBR}$ ratio) showing partial retention of micropollutants by a gel layer of laccase on the UF-membrane during continuous-flow operation of UF-EMBR. Data presented as average \pm standard deviation $(n=6)$. The average and standard deviation were calculated based on the duplicate samples collected at 16, 32 and $48 \mathrm{~h}$.

Figure 4. Degradation of micropollutants in UF- and NF-EMBRs operated separately at an HRT of $16 \mathrm{~h}$ and micropollutant loading rate of $1.44 \mathrm{mg} / \mathrm{L} \mathrm{d}$. Data presented as average \pm standard deviation $(n=6)$. The contribution of enzymatic degradation to overall removal was calculated by using the equation (3).

Figure 5. Figure 5. Time course of micropollutant degradation by laccase in continuous-flow UF- and NF-EMBRs. Each data point denotes average of two samples with a variation of less than $5 \%$.

Figure 6. Normalized permeate flux achieved by continuous-flow operation of UF- and NFEMBRs as a function of filtration time at a cross-flow velocity of $40.2 \mathrm{~cm} / \mathrm{s}$. Temperature of the enzymatic bioreactor was maintained at $25^{\circ} \mathrm{C}$. 
(a) Full recirculation mode

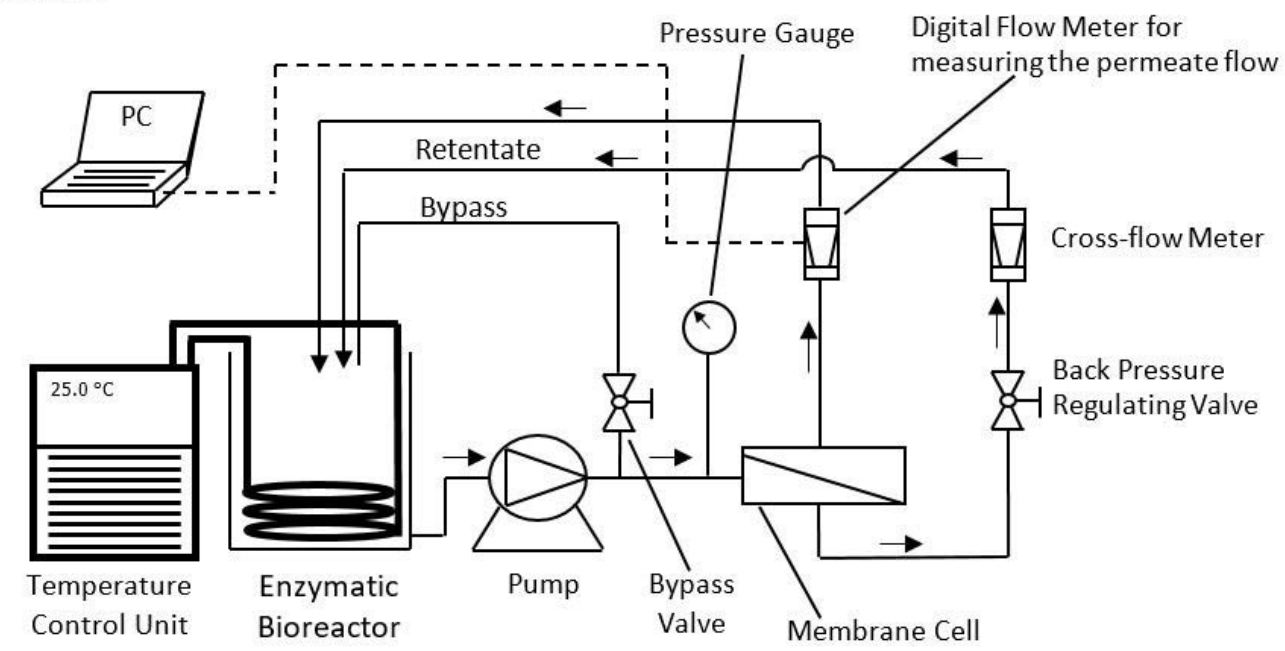

(b) Continuous-flow mode

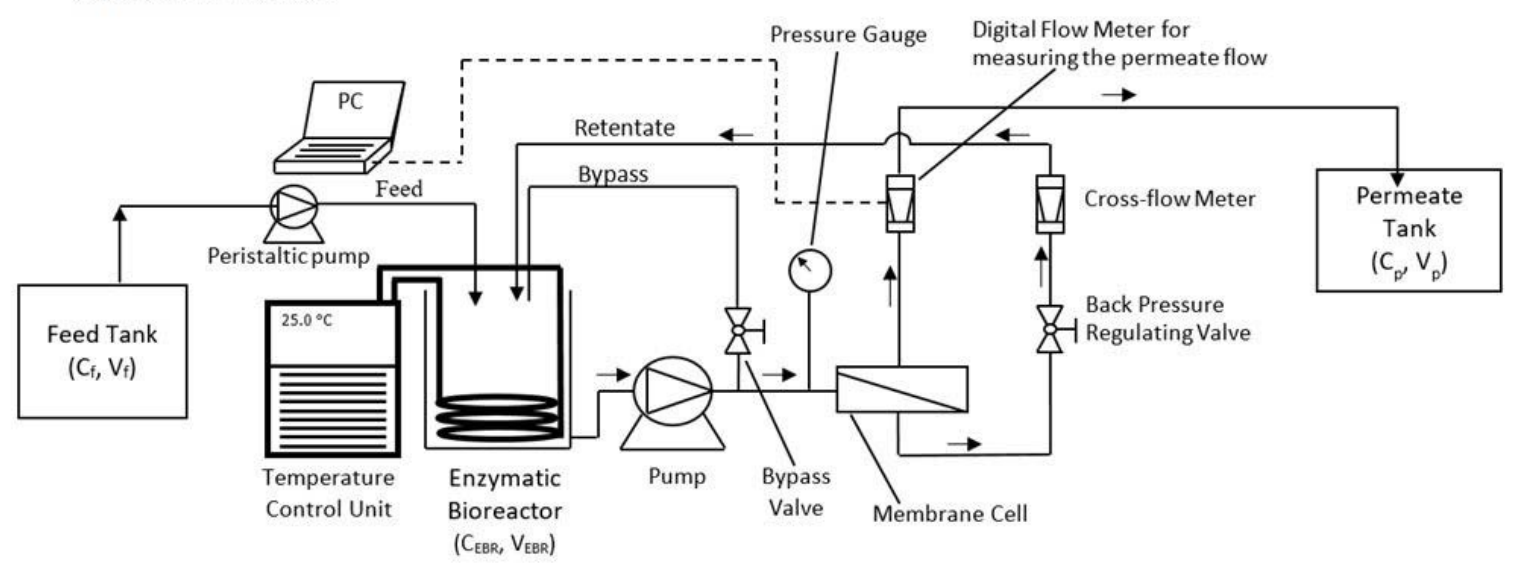

Figure 1. Schematics of the lab-scale cross-flow filtration system attached to an enzymatic bioreactor operated in full recirculation mode (a) and continuous-flow mode (b). Arrows show the direction of flow. Laccase retention was first confirmed with a short term (i.e., $24 \mathrm{~h}$ ) study in full recirculation mode. Further operation of EMBRs were conducted in continuous-flow mode for assessing the impact of micropollutant retention on their degradation. $\mathrm{C}_{\mathrm{f}}, \mathrm{C}_{\mathrm{EBR}}$ and $\mathrm{C}_{\mathrm{p}}$ are the concentration $(\mu \mathrm{g} / \mathrm{L})$ of a specific micropollutant in the feed, enzymatic bioreactor and permeate, respectively. $V_{f}, V_{\text {EBR }}$ and $V_{p}$ represent the volume of feed, enzymatic bioreactor and permeate, respectively. A picture of lab-scale EMBR is shown in Supplementary data 


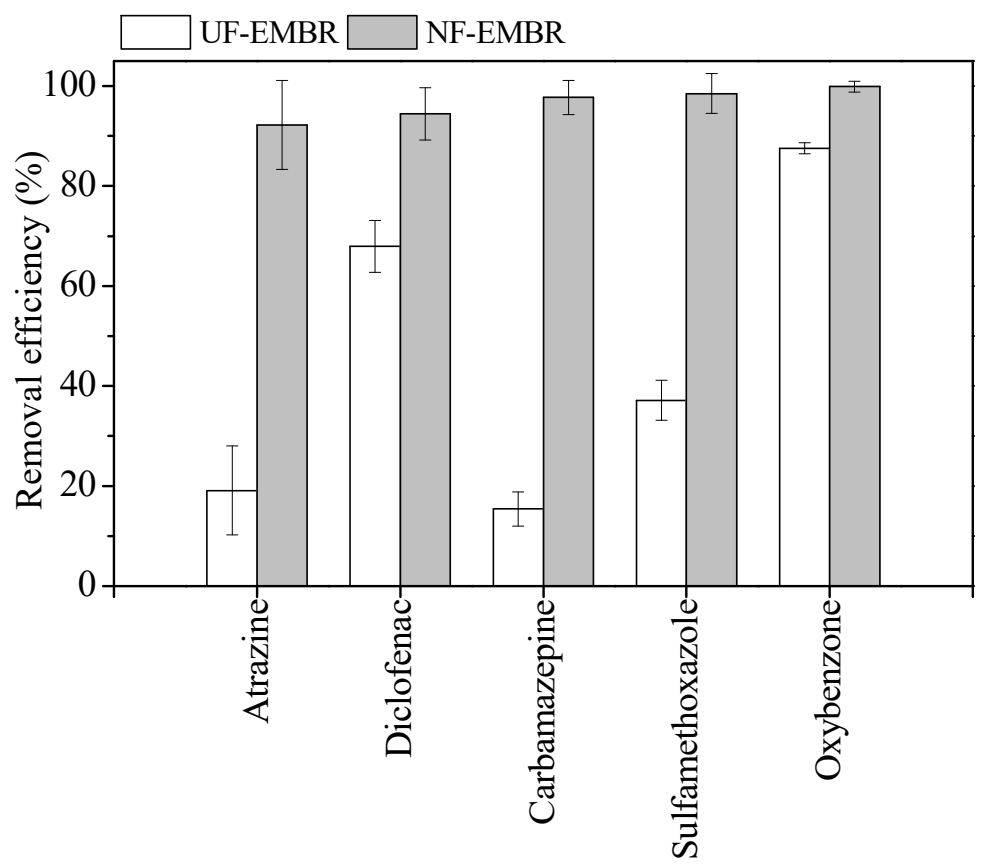

Figure 2. Overall removal (i.e., degradation + membrane retention) of micropollutants in UFand NF-EMBRs operated separately at an HRT of $16 \mathrm{~h}$ and micropollutant loading rate of 1.44 $\mathrm{mg} / \mathrm{L} \mathrm{d}$. Data presented as average \pm standard deviation $(\mathrm{n}=6)$. 


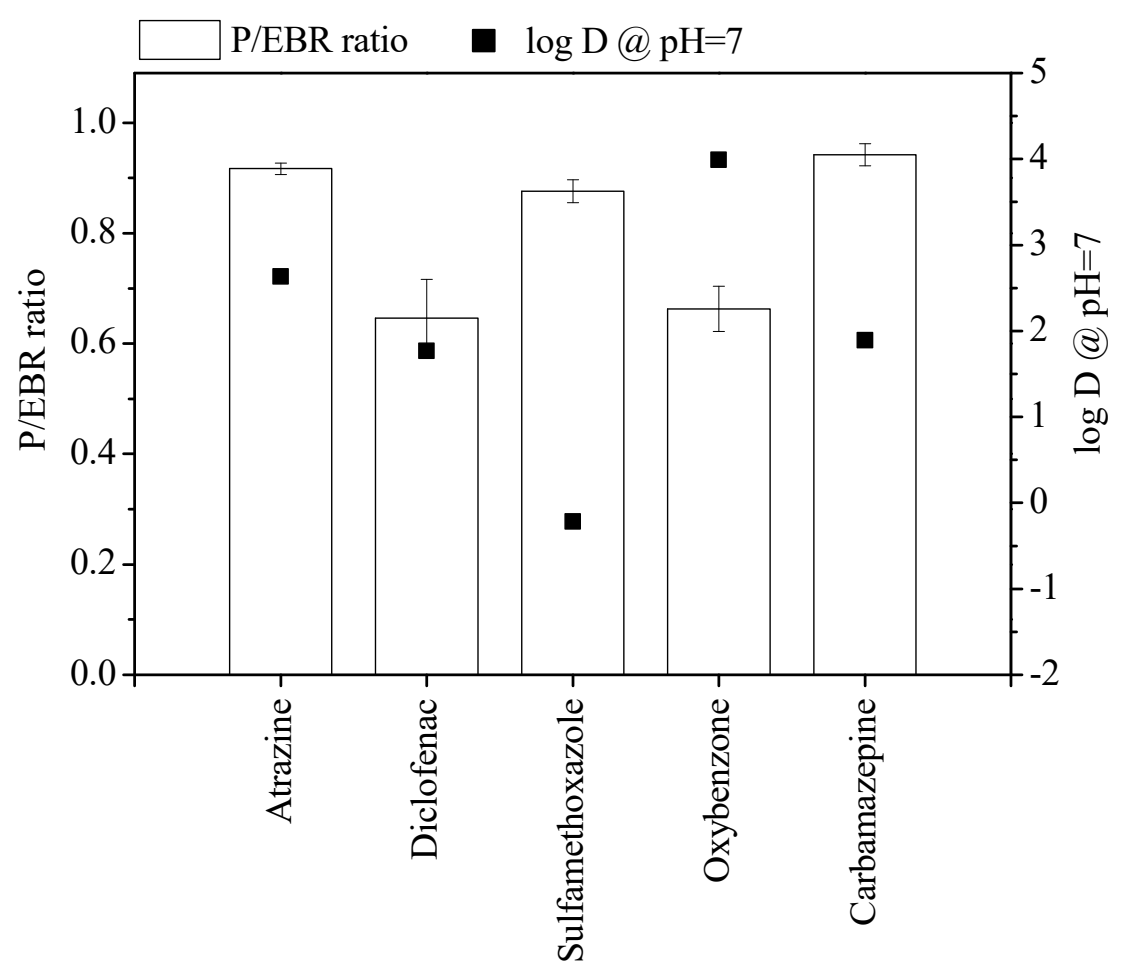

Figure 3. Concentration ratio between membrane permeate and enzymatic bioreactor (P/EBR ratio) showing partial retention of micropollutants by a gel layer of laccase on the UF-membrane during continuous-flow operation of UF-EMBR. Data presented as average \pm standard deviation $(n=6)$. 


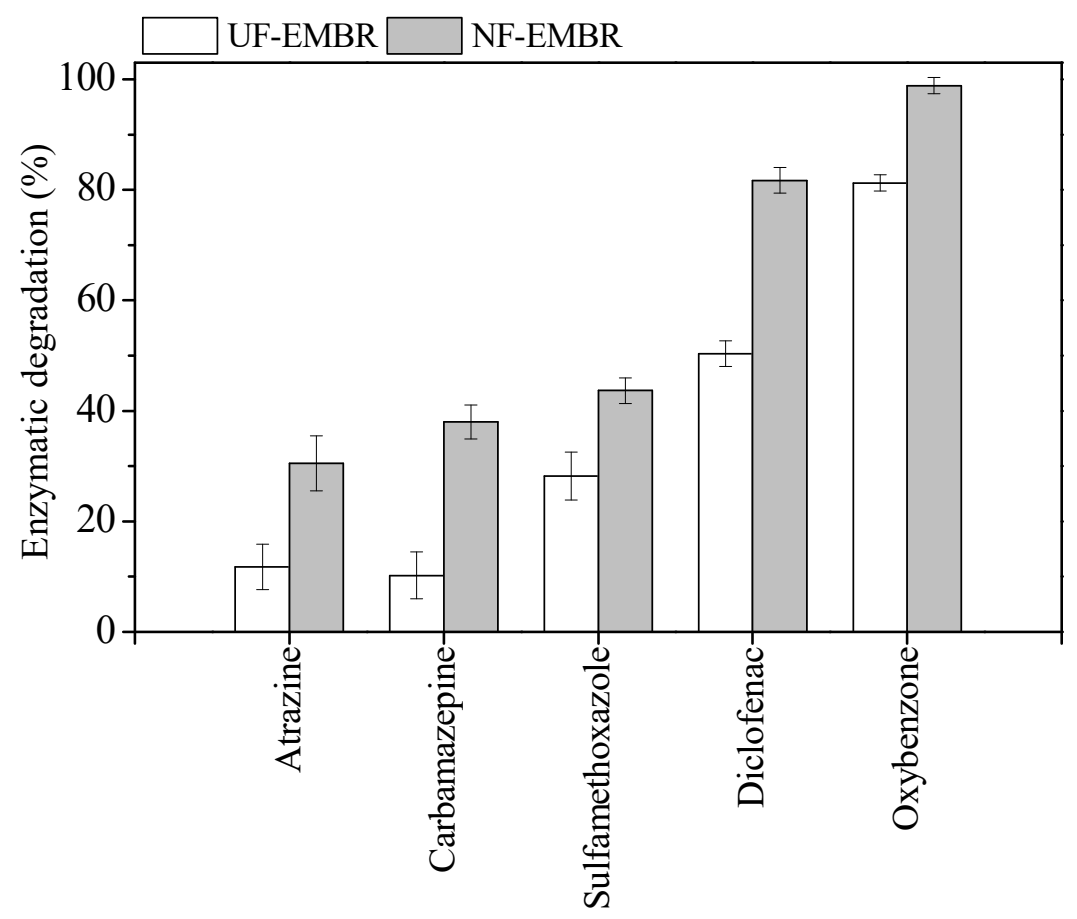

Figure 4. Degradation of micropollutants in UF- and NF-EMBRs operated separately at an HRT of $16 \mathrm{~h}$ and micropollutant loading rate of $1.44 \mathrm{mg} / \mathrm{L} \mathrm{d}$. Data presented as average \pm standard deviation $(n=6)$. The contribution of enzymatic degradation to overall removal was calculated by using the equation (3). 

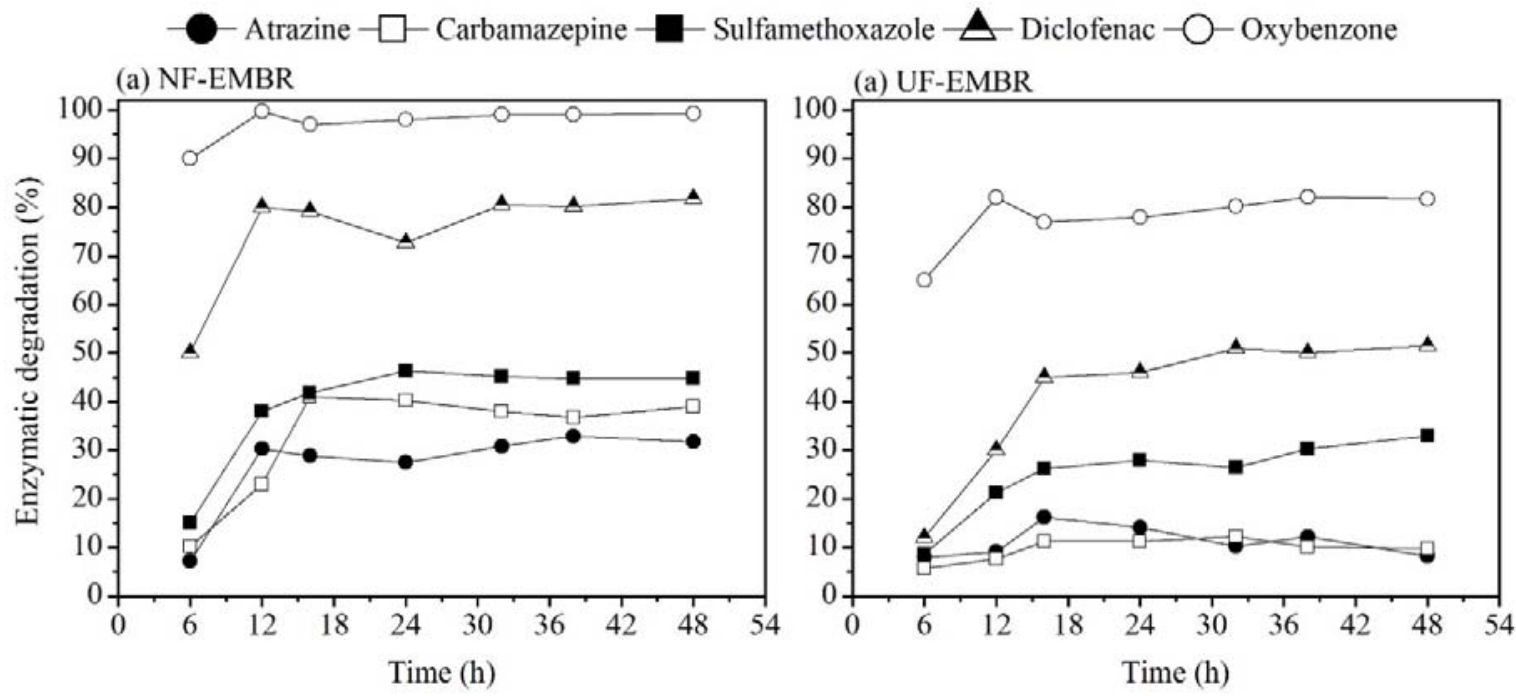

Figure 5. Time course of micropollutant degradation by laccase in continuous-flow UF- and NFEMBRs. Each data point denotes average of two samples with a variation of less than $5 \%$. 


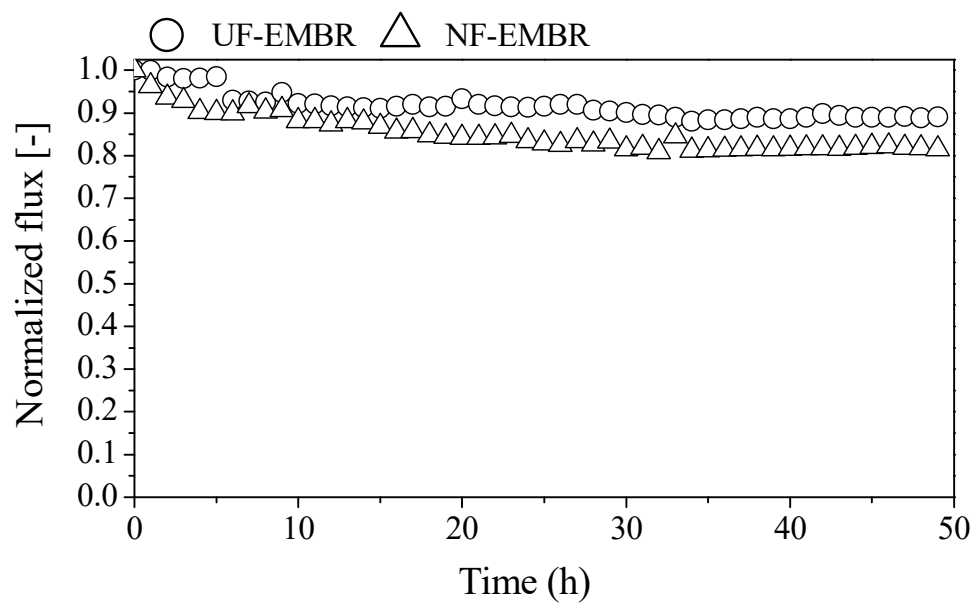

Figure 6. Normalized permeate flux achieved by continuous-flow operation of UF- and NFEMBRs as a function of filtration time at a cross-flow velocity of $40.2 \mathrm{~cm} / \mathrm{s}$. Temperature of the enzymatic bioreactor was maintained at $25^{\circ} \mathrm{C}$. 


\section{Impact of simultaneous retention of micropollutants and laccase on micropollutant degradation in enzymatic membrane bioreactor}

Muhammad B. Asif ${ }^{1}$, Faisal I. Hai ${ }^{1, *}$, Bipro R. Dhar ${ }^{2}$, Huu H. Ngo $^{3}$, Wenshan Guo ${ }^{3}$, Veeriah Jegatheesan ${ }^{4}$, William E. Price ${ }^{5}$ and Long D. Nghiem ${ }^{1,3}$, Kazuo Yamamoto ${ }^{6}$

1 Strategic Water Infrastructure Lab, School of Civil, Mining and Environmental Engineering, University of Wollongong, Wollongong NSW 2522, Australia.

2 Department of Civil and Environmental Engineering, School of Mining \& Petroleum Engineering, University of Alberta, Edmonton, AB T6G 1H9, Canada

${ }^{3}$ Centre for Technology in Water and Wastewater, School of Civil and Environmental Engineering, University of Technology Sydney, Sydney, NWS 2007, Australia

${ }^{4}$ School of Engineering, RMIT University, Melbourne, VIC 3000, Australia

5 Strategic Water Infrastructure Lab, School of Chemistry, University of Wollongong, Wollongong NSW 2522, Australia.

6 Environmental Science Centre, Department of Urban Engineering, University of Tokyo, Tokyo 113-0033, Japan

* Corresponding author: faisal@uow.edu.au; Tel.: +61-2-42213054 


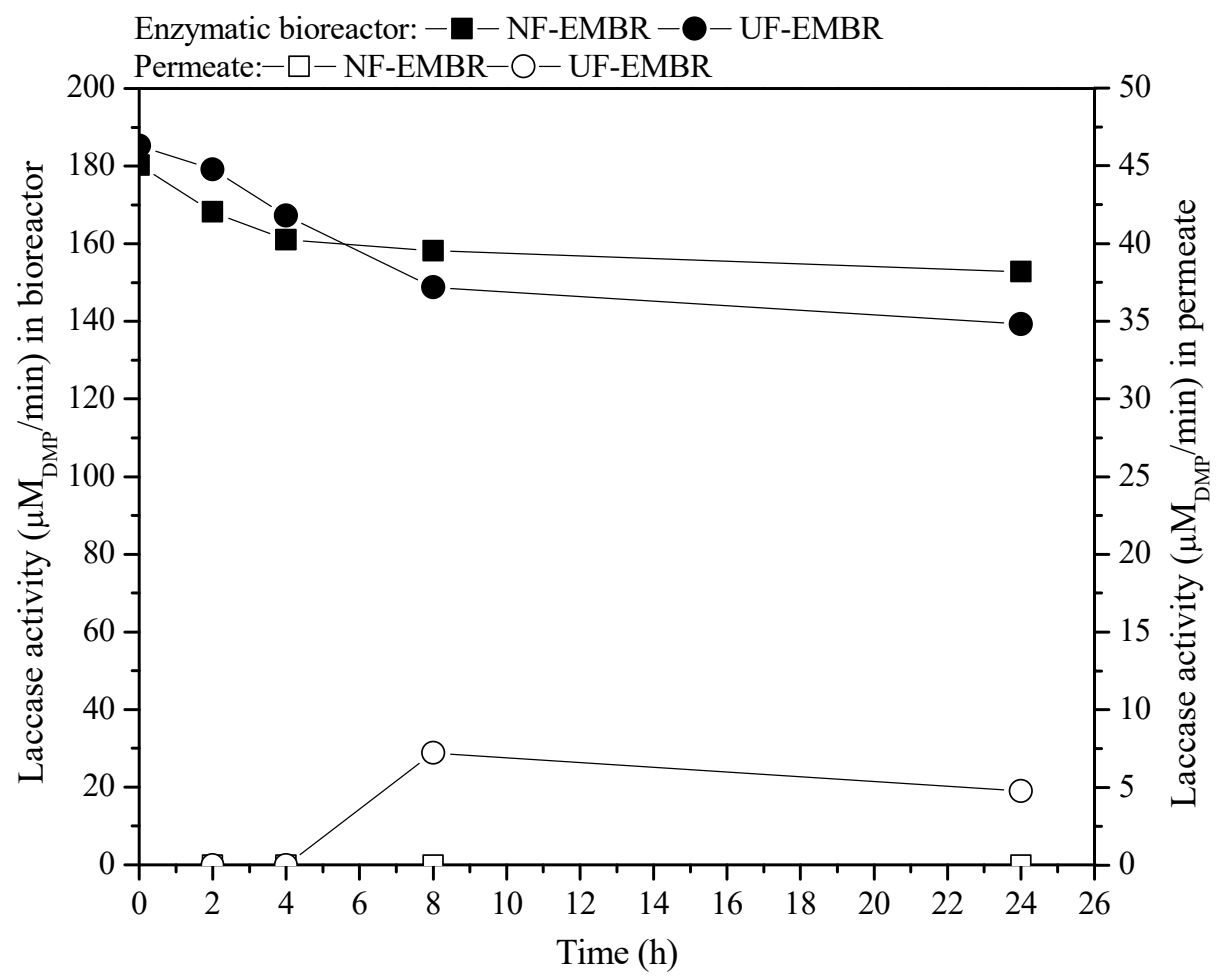

1. Figure S1. Laccase activity in the enzymatic bioreactor and permeate of UF-EMBR and NFEMBR during their operation in full recirculation mode. The standard deviation of duplicate samples was less than $2 \%$. 

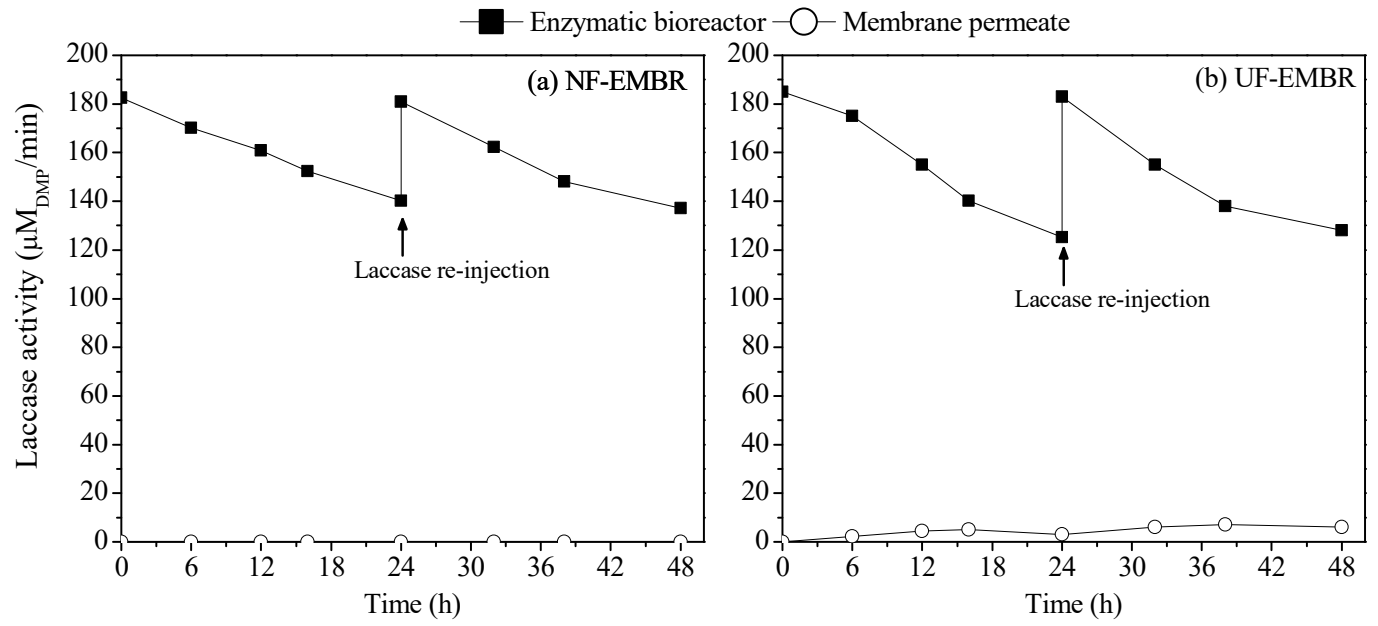

2. Figure S2. Figure S2. Laccase activity in the enzymatic bioreactor and in membrane-permeate in continuous-flow UF-EMBR and NF-EMBR. The standard deviation of duplicate samples was less than $5 \%$. 


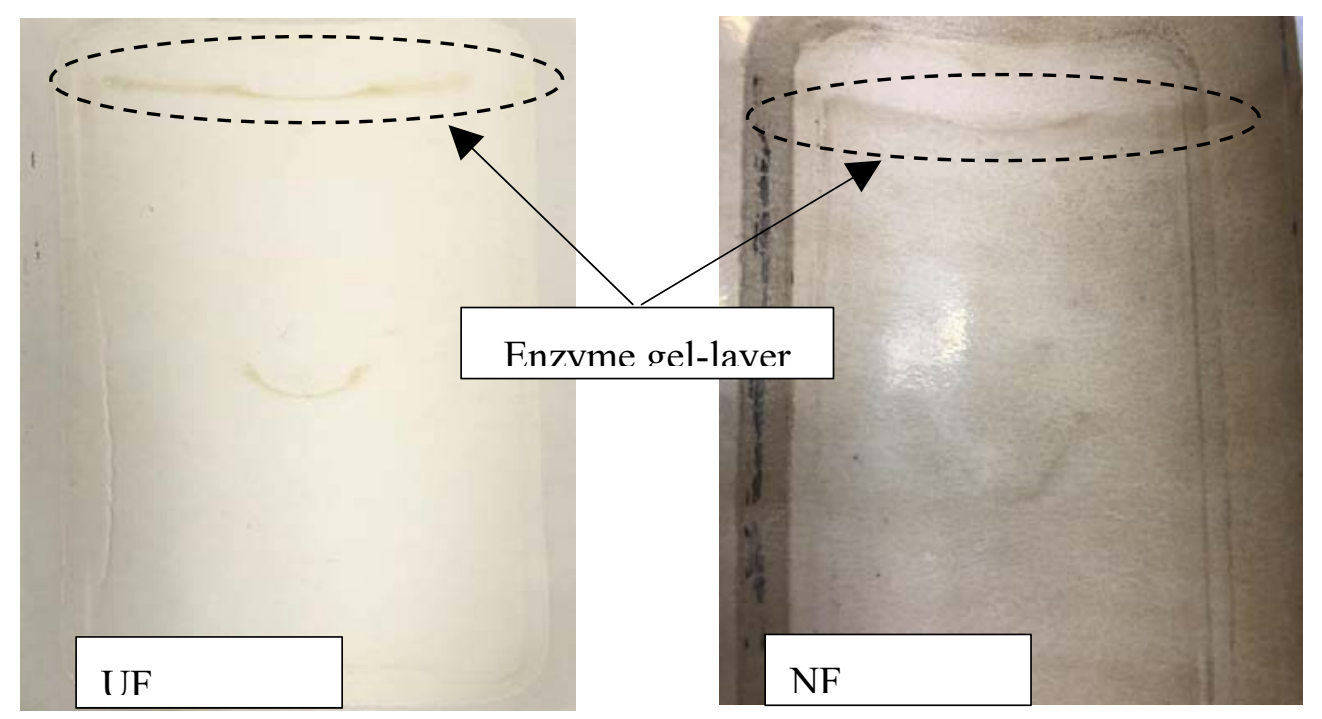

3. Figure S3. Enzyme-gel layer formed on the surface of the UF and NF membrane during the operation of UF- and NF-EMBRs. 


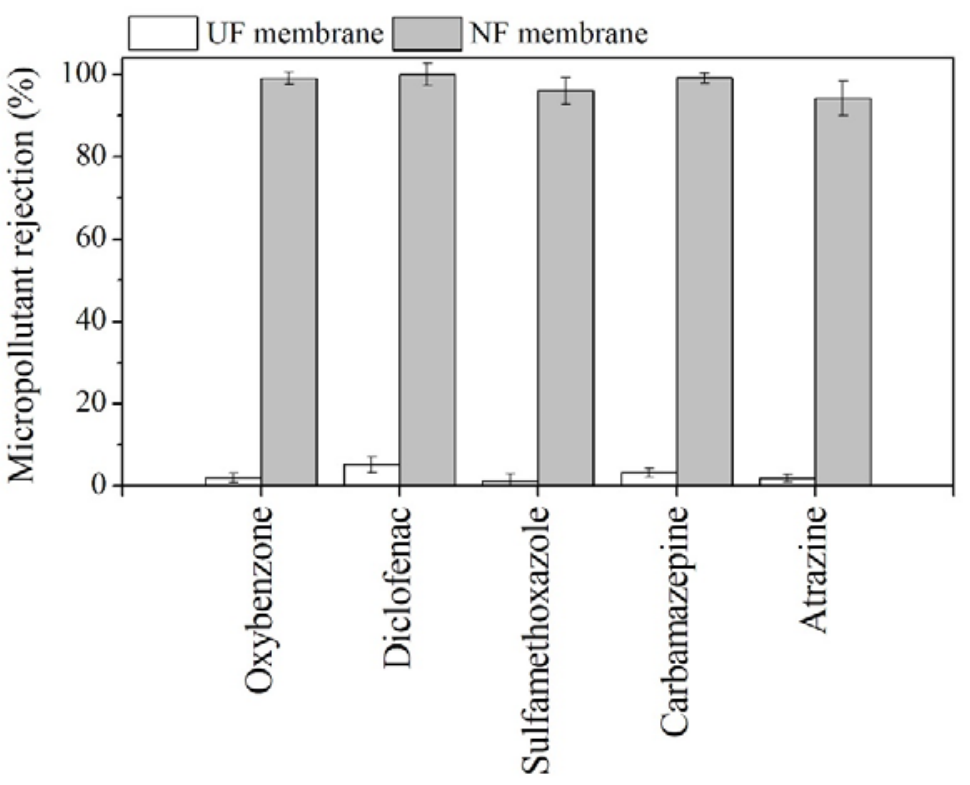

5. Figure S4. Rejection of micropollutants by the UF and NF membrane during the operation of EMBRs in full recirculation mode. Error bars show average \pm standard deviation $(n=8)$. 


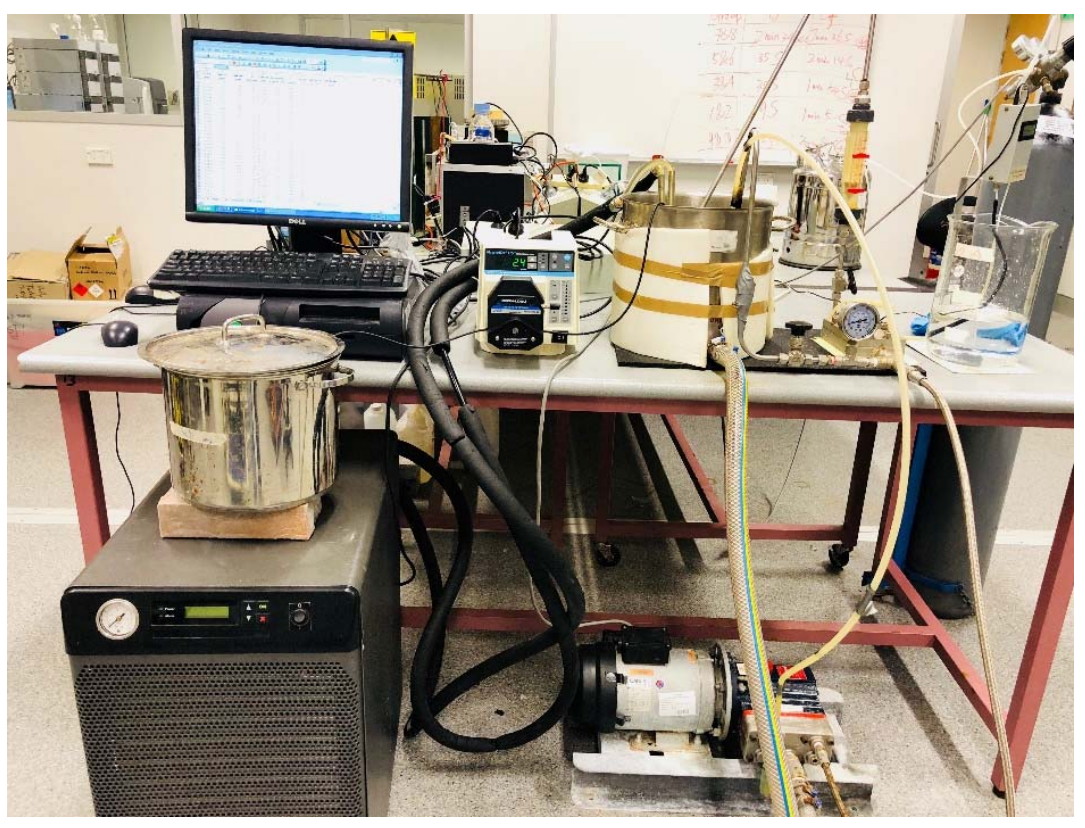

6. Figure S5. Lab-scale enzymatic membrane bioreactor 